\title{
LEGISLAÇÃO AMBIENTAL INCIDENTE SOBRE CEMITÉRIOS DO ESTADO DE SÃO PAULO
}

\author{
Luís Augusto Gomes Rocha'
}

\section{Luiz César Ribas ${ }^{2}$}

Jeomar Bello ${ }^{3}$

RESUMO: A expansão urbana acarreta a necessidade de mitigações ambientais, em que um planejamento do uso do solo, bem como seu processo de ocupação traz a necessidade também de estudos para viabilizar tais ações. Nesse processo de expansão, os cemitérios necessitam de maiores atenções, já que evidenciaram indícios de contaminações no solo e fontes de água próximas. Atualmente, o CONAMA (Conselho Nacional de Meio Ambiente) possui duas resoluções que discorrem sobre os aspectos construtivos, visando controlar os resíduos existentes, tais como o Liquame da Coliquação (também conhecido por Necrochorume), um dos responsáveis pela contaminação do solo e aquíferos subterrâneos. Tendo esse escopo em pauta, este trabalho exibe um levantamento da legislação que incide sobre a implantação e regularização de cemitérios no estado de São Paulo.

Palavras chave: Cemitérios. Estudo de Viabilidade Ambiental. Legislação

\footnotetext{
${ }^{1}$ Engenheiro Florestal - Faculdade de Ciências Agronômicas - Unesp / Botucatu, lagrocha@fca.unesp.br

2 Engenheiro Florestal - Prof. Dr. do Dep. de Economia e Sociologia, Faculdade de Ciências Agronômicas, Unesp / Botucatu, Icribas@fca.unesp.br

${ }^{3}$ Gestão Ambiental - Faculdade Metropolitanas Unidas - SFMSP - Departamento Técnico de Cemitérios, jeomabello@prefeitura.sp.gov.br
} 


\section{INTRODUÇÃO}

No processo de instalação de um empreendimento, existe a necessidade de evitar ou mitigar qualquer eventual dano ambiental que ele possa causar. Tais possíveis passivos ambientais elevam os custos da implantação e ainda alteram significativamente o seu cronograma, acarretando sérios prejuízos e, muitas vezes, comprometendo a própria viabilidade. Com um dispositivo norteador, o empreendedor poderá minimizar estas surpresas pós-planejamento, adotando um estudo de viabilidade ambiental, e, desta forma, avaliar a viabilidade técnicofinanceira da iniciativa, obtendo as características ambientais da área em função das restrições definidas nos dispositivos legais.

Dentro desse escopo, é pertinente salientar que vários empreendimentos implantados antes desses dispositivos não levam em conta os aspectos ambientais, pois não tinham diretrizes a seguir. Desta forma, muitos cemitérios no seu período de implantação não contavam com legislação pertinente, carecendo assim de regularização. Essa necessidade de regularizar é descrita em Kemerich (2010), que afirma que os cemitérios em geral são um grave problema para a proteção das águas subterrâneas nos centros urbanos, já que os cemitérios podem alterar a qualidade dessas águas devido à infiltração e percolação das águas pluviais através dos túmulos e do solo que, por conseguinte, ocasiona a lixiviação de uma série de compostos químicos orgânicos e inorgânicos ao longo da zona não saturada, podendo alguns destes compostos atingir a zona saturada e, portanto, poluir 0 aquífero.

No processo de regularização dessas áreas, a legislação recai sobre o tema abrangendo a análise de aspectos ambientais e urbanísticos, tais como o Estatuto da Cidade, Plano Diretor Estratégico, Plano Regional Estratégico, uso e ocupação do solo, legislação sobre passeios públicos; ambientais, recursos hídricos, drenagem e saneamento ambiental, uso racional da água e reuso, remoção e recomposição de vegetação, áreas contaminadas, parâmetros de incomodidade, 
proteção de patrimônio histórico e cultural. Essa legislação incidente deve respeitar as três esferas do poder judicial, citando-se as legislações de âmbito federal, estadual e municipal.

A base inicial é pautada dentro da Política Nacional do Meio Ambiente, instituída pela Lei Federal 6938, de 31 agosto de 1981, conforme artigo 9丷, inciso III, que determina a realização de avaliação ambiental como um instrumento da PNMA; da Resolução CONAMA n.. 237/97, que normatizou os procedimentos para Licenciamento Ambiental. Em consonância também estão as Resoluções CONAMA $n^{\circ} 335 / 03,368 / 06$ e 402/08, que dispõem sobre o licenciamento ambiental de cemitérios.

O objetivo central da regularização dos passivos ambientais é atestar a viabilidade ambiental do empreendimento, por meio da caracterização do mesmo, conhecendo e analisando a situação atual da área suscetível a sofrer a ação, devido à sua operação - as denominadas áreas de influência, para o posterior estudo comparativo entre a situação atual e a situação futura. Essa análise é realizada por meio da identificação e avaliação dos impactos ambientais potenciais, decorrentes das obras e funcionamento do empreendimento. Tal avaliação considera a proposição de ações e gestão dos impactos, que visam minimizar e/ou eliminar as alterações negativas, e incrementar os benefícios trazidos pela manutenção do empreendimento.

\section{LEGISLAÇÃO INCIDENTE}

Dada a complexidade que assumem as questões legais quando se trata de cemitérios (já implantados e funcionando há muito tempo), é necessário contemplar questões históricas, culturais e religiosas, em concordância com a Legislação Ambiental. Desta forma, exibe-se abaixo um apanhado da legislação utilizada na regularização dos cemitérios municipais da cidade de São Paulo dentro das esferas federal, estadual e municipal. 


\section{LEGISLAÇÃO FEDERAL}

A legislação ambiental brasileira, visando o direito de todos a um ambiente sadio, conforme estabelecido na Constituição Federal de 1988, regulamentou a necessidade da análise de impactos ambientais de projetos que explorem os recursos naturais e alterem a paisagem.

No caso das ações e atividades modificadoras do meio ambiente, urbanas ou rurais, a legislação brasileira prevê a elaboração de documentos técnicos específicos, a serem submetidos aos órgãos ambientais para licenciamento. $\mathrm{Na}$ análise do contexto dessa legislação ambiental, no caso de empreendimento urbano, sobretudo de intervenção em área já urbanizada, são perseguidos os seguintes objetivos:

- acompanhar o desenvolvimento da proposta de intervenção para a qualificação ambiental da área, em conformidade com objetivos, diretrizes e prioridades estabelecidas na lei do plano diretor estratégico;

- orientar o processo de licenciamento ambiental, de forma a garantir a publicidade aos estudos ambientais e a participação da sociedade civil, que poderá contribuir nas propostas em estudo;

- conceber os estudos ambientais, sobretudo, a avaliação dos impactos ambientais, com uma perspectiva de gestão ambiental urbana;

- relacionar a legislação ambiental e urbana com os planos e programas co-localizados.

A Carta Magna, ao impor como condicionante do licenciamento de atividades potencialmente deterioradoras do ambiente, determina a exigência de um prévio Estudo de Impacto Ambiental e atribuiu um papel maior às normas vigentes 
sobre a matéria, desde o advento da Lei Federal 6.938/81, que instituiu a Política Nacional de Meio Ambiente (PNMA), e da Resolução do Conselho Nacional do Meio Ambiente (CONAMA) 01/86.

Dentro desse contexto, elucida-se a legislação federal referente a tópicos cemiteriais:

- Lei Federal ํㅜ 6.938/81 - artigo 2º , incisos VII, VIII, IX e X e artigos 9 e 10 - Estabelece a Politica Nacional do Meio Ambiente;

- Constituição da República Federativa de 1988, artigo 225, IV;

- Art. 225. Todos têm direito ao meio ambiente ecologicamente equilibrado, bem de uso comum do povo e essencial à sadia qualidade de vida, impondo ao Poder Público e à coletividade o dever de defendê-lo e preservá-lo para as presentes e futuras gerações.

○ $\S 1^{\circ}$ - Para assegurar a efetividade desse direito, incumbe ao Poder Público:

- IV - exigir, na forma da lei, para instalação de obra ou atividade potencialmente causadora de significativa degradação do meio ambiente, estudo prévio de impacto ambiental, a que se dará publicidade;

- Resolução CONAMA n 1, de 23/01/86 - Define roteiro para elaboração de Estudo de Impacto Ambiental e Relatório de Impacto Ambiental - EIA/RIMA.

- Resolução CONAMA n 06, de 24/01/86; - Aprovar os modelos de publicação de pedidos de licenciamento em quaisquer de suas modalidades, sua renovação e a respectiva concessão e aprova os novos modelos para publicação de licenças.

- Resolução CONAMA no 237, de 19/12/97 - Dispõe sobre licenciamento ambiental; competência da União, Estados e Municípios; listagem de atividades sujeitas ao licenciamento; 
Estudos Ambientais, Estudo de Impacto Ambiental e Relatório de Impacto Ambiental.

- Resolução CONAMA no 335, de 03/04/03 - Dispõe sobre o licenciamento ambiental de cemitérios.

- Resolução CONAMA no 368, de 28/03/06 - Altera dispositivos da Resolução $n^{\circ} 335$, de 3 de abril de2003, que dispõe sobre 0 licenciamento ambiental de cemitérios.

- Resolução CONAMA no 402, de 17/11/08 - Altera os artigos 11 e 12 da Resolução no 335,de 3 de abril de 2003.

- LEI 11.445/2007 - de 05/01/2007 - estabelece diretrizes nacionais para o saneamento básico; altera as leis $n^{\circ} 6.766$, de 19 de dezembro de 1979, 8.036, de 11 de maio de 1990, 8.666, de 21 de junho de 1993, 8.987, de 13 de fevereiro de 1995; revoga a lei $n^{\circ} 6.528$.

- LEI 10.257/2001 (Estatuto das Cidades) - 10/07/2001 regulamenta os arts. 182 e 183 da constituição federal, estabelece diretrizes gerais da política urbana e dá outras providências.

- LEI 9.074/1995 - 07/07/1995 - estabelece normas para outorga e prorrogações das concessões e permissões de serviços públicos e dá outras providências.

\section{LEGISLAÇÃO ESTADUAL}

A discussão sobre o nível de competência ${ }^{4}$ passou por adequação nos últimos anos, no que tange a atuação da União, estados, Distrito Federal e municípios. Essa alteração trata de um ato administrativo pelo qual o órgão ambiental competente estabelece as condições, restrições e medidas de controle ambiental que deverão ser obedecidas pelo empreendedor, pessoa física ou jurídica. Essa configuração já tinha sido elencada no artigo $23^{\circ}$ da Constituição

${ }^{4}$ Art. $1^{\circ}$ II da Resolução 237 CONAMA 
Federal, atribuindo competência comum a todos os entes federados, ou seja, da União, dos Estados, do Distrito Federal e dos municípios.

Segundo Dullius (2013), "a definição das competências é de extrema importância para que se possa saber quais são as entidades responsáveis pela fiscalização de determinados setores da vida social”.

Nesse contexto, buscando instruções nos órgãos ambientais do estado de São Paulo encontramos:

- Lei Complementar no 94, de 29/05/74 - Define normas acerca dos aspectos comuns que cercam os interesses dos municípios que compõem a RMSP (Região Metropolitana de São Paulo). Dentre eles, merecem destaque, para os fins deste relatório, os itens III e VI do artigo 2ํㅡ, aproveitamento dos recursos hídricos e controle da poluição ambiental, na forma que dispuser a lei federal, respectivamente.

Constituição do Estado de São Paulo, de 05/10/89 Ressalta-se os seguintes artigos e aspectos:

- Artigo 201 - estímulo à criação de consórcios intermunicipais, objetivando a solução de problemas comuns relativos à proteção ambiental;

- Artigo 210 - trata de incentivos do Estado para a adoção, pelos municípios, de medidas no sentido de: zoneamento de áreas inundáveis, com restrições a usos incompatíveis nas áreas sujeitas a inundações frequentes e manutenção da capacidade de infiltração do solo; Instituição de programas permanentes de racionalização do uso das águas destinadas ao abastecimento público e industrial e à irrigação, assim como de combate às inundações e à erosão; 
- Artigo 42 das Disposições Transitórias: "O Estado, no exercício da competência prevista no artigo 24, incisos VI, VII e VIII da Constituição Federal, no que couber, elaborará, atendendo suas peculiaridade, o Código de Proteção ao Meio Ambiente, no prazo de 180 dias".

- Lei no 997, de 31/05/76 - Dispõe sobre controle de poluição do meio ambiente.

- Decreto o 8468, de 08/09/76 (e legislação correlativa) Regulamenta a Lei no 997/76 (controle da poluição do meio ambiente)

- Resolução SMA 01/10- Define procedimentos para o licenciamento ambiental de obras na área de influência do rio Tietê.

- Resolução SMA 14/10 - Define as diretrizes técnicas para o licenciamento de empreendimentos em áreas potencialmente críticas para a utilização de água subterrânea.

- Resolução SMA 18/07- Disciplina procedimentos para a autorização

de supressão de exemplares arbóreos nativos isolados

- Resolução SMA 22/07 - Dispõe sobre a execução do Projeto Ambiental Estratégico "Licenciamento Ambiental Unificado", que visa integrar e unificar o licenciamento ambiental no Estado de São Paulo, altera procedimentos para o licenciamento das atividades que especifica e dá outras providências.

- Resolução SMA 22/09 - Dispõe sobre a apresentação de certidões municipais de uso e ocupação do solo, sobre o exame e manifestação técnica pelas Prefeituras Municipais nos processos de licenciamento ambiental realizado no âmbito do SEAQUA e sobre a concessão de Licença de Operação para empreendimentos existentes e dá outras providências. 
- Resolução SMA no 42, de 29/12/94 - Define que, nos casos previstos no artigo $2^{0}$ da Resolução CONAMA no 1/86, 0 interessado requererá a licença ambiental instruída com Relatório Ambiental Preliminar - RAP, conforme roteiro de orientação estabelecido pela Secretaria de Estado do Meio Ambiente - SMA.

\section{LEGISLAÇÃO MUNICIPAL}

Conforme 0 artigo 23 da Constituição Federal, os municípios têm competência administrativa para defender o meio ambiente e combater a poluição. Em maio de 2007, foi promulgada pela Secretaria Estadual de Meio Ambiente a Resolução SMA no 22/07, que dispõe sobre a execução do Projeto Ambiental Estratégico "Licenciamento Ambiental Unificado", visando integrar e unificar o licenciamento ambiental no Estado de São Paulo. A Secretaria do Verde e do Meio Ambiente (SVMA) foi criada em 1993 (Lei n. 11426/93), com as atribuições de:

- planejar, ordenar e coordenar as atividades de defesa do meio ambiente no Município de São Paulo, definindo critérios para conter a degradação e a poluição ambiental;

- manter relações e contatos visando à cooperação técnicocientífica com órgãos e entidades ligados ao meio ambiente, do Governo Federal, dos Estados e dos Municípios brasileiros, bem como com órgãos e entidades internacionais;

- estabelecer com os órgãos federal e estadual do Sistema Nacional do Meio Ambiente - SISNAMA critérios visando à otimização da ação de defesa do meio ambiente no Município de São Paulo.

Dentro dessas atribuições, exibimos os instrumentos que guardam relação com o tema cemiterial: 
Plano Diretor Municipal: é o instrumento básico da política de desenvolvimento e expansão urbana, e pode ser considerado um instrumento de política municipal do meio ambiente, uma vez que o crescimento do município deve ser compatível com a proteção ambiental. Através dele, pode-se, por exemplo, prever a expansão do sistema de drenagem de águas pluviais através de técnicas não agressivas ao meio ambiente.

Lei de Uso e Ocupação do Solo: é o instrumento controlador do uso da terra. Através dela, pode-se, por exemplo, prever o afastamento de atividades que acarrete assoreamento ou poluição dos corpos d'água de áreas problemáticas ou, mesmo, exercer controle sobre os padrões de ocupação de zonas com uso sujeito à erosão.

Lei de Parcelamento de Solo Urbano: através desse instrumento, o município pode proibir ou limitar fortemente a ocupação de áreas alagadiças, ou fixar normas para a rede viária, e de tamanho de lotes, minimizando os riscos de erosão e assoreamento.

Código de Obras: permite adequar a localização dos empreendimentos, evitando grandes áreas de impermeabilização de solo, que impedem a infiltração das águas pluviais.

Código de Posturas: instrumento que disciplina o uso do espaço público ou de uso coletivo. Através dele pode-se, por exemplo, exigir a limpeza e o cercamento de terrenos vazios.

\section{CONCLUSÃO}

O sistema de competências tem como pauta o equilíbrio federativo e dividese em material e legislativa, que se complementam. Para a proteção do meio ambiente, o Município tem competência material comum, assim como, a legislativa suplementar, podendo detalhar, restringir ou especificar mais a norma, que deve ser 
mais protetiva e decorrente de assuntos de interesse local. Porém, por vezes, o que se nota são sobreposições administrativas ou atuações muito semelhantes entre os órgãos e instituições federais, estaduais e municipais, sem uma definição clara das áreas de atuação inerentes a cada uma delas.

Um exemplo claro foi a Portaria SVMA ${ }^{5} 44 / 10$ frente a Resolução SMA $18 / 07$, onde em alguns temas a lei municipal não se apresenta de forma mais restritiva do que a instrução na esfera estadual.

Outro ponto é a Norma ABNT NBR 10004, que estabelece os resíduos nos estados sólido e semi-sólido, resultantes de atividades de origem industrial, doméstica, hospitalar, comercial, agrícola, de serviços e de varrição, devem ter seu translado efetuado em caminhões específicos; o que também é afirmado pela CONAMA n`358, em seu artigo 16, que discorre que resíduos de sepultamentos em cemitérios devem ser tratados como do Grupo $\mathrm{A}^{6}{ }^{6}$. Desta forma, todos os resíduos oriundos dos procedimentos de exumação e sepultamento deveriam ser retirados dos cemitérios por caminhões específicos. Contudo, outra sobreposição administrativa foi visualizada tendo na Resolução da Secretaria Estadual de Saúde 28/2013, em seu art. $11^{\circ}$,

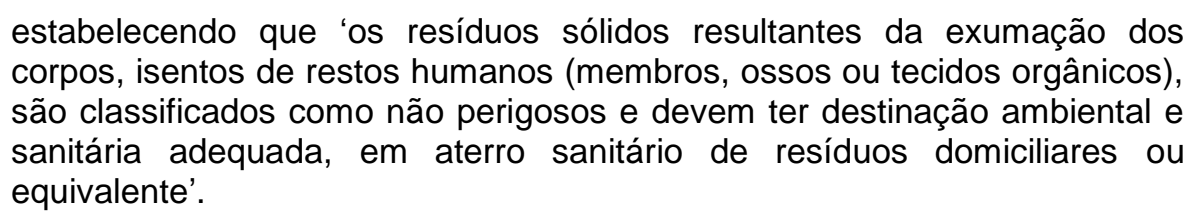

Por mais que tenhamos apresentado em sua grande maioria a legislação que incide sobre o tema cemiterial, é evidente que por se tratar de um procedimento de licenciamento ambiental, cada situação se apresenta de uma forma diferente, salientando que não existe um único esquema para o desenvolvimento sustentável. Mesmo tendo citados as esferas federal, estadual e municipal os sistemas econômicos e sociais diferem de uma região para outra, cada município deve avaliar

\footnotetext{
${ }^{5}$ Disciplina critérios e procedimentos de compensação ambiental pelo manejo por corte, transplante, ou qualquer outra intervenção ao meio ambiente no município de São Paulo

${ }^{6}$ Tais resíduos devem ser submetidos a processo de tratamento com redução de carga microbiana compatível.
} 
as implicações concretas de suas políticas. Mas, apesar dessas diferenças, a busca pelo zelo ambiental deve ser encarada como um objetivo de todos.

\section{REFERENCIAL}

Decreto no 8468, de 08/09/76 (e legislação correlativa) - Regulamenta a Lei no 997/76 (controle da poluição do meio ambiente)

Dullius A.A, Boschetti F.- Competências e desafios do licenciamento ambiental Ambito Juridico - 2013

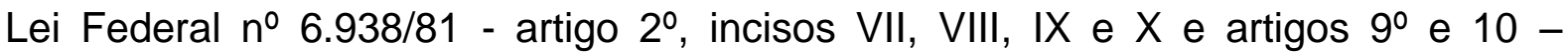
Estabelece a Politica Nacional do Meio Ambiente;

Resolução CONAMA nำ 1, de 23/01/86 - Define roteiro para elaboração de Estudo de Impacto Ambiental e Relatório de Impacto Ambiental - EIA/RIMA.

Resolução CONAMA n 06, de 24/01/86; - Aprovar os modelos de publicação de pedidos de licenciamento em quaisquer de suas modalidades, sua renovação e a respectiva concessão e aprova os novos modelos para publicação de licenças.

Resolução CONAMA no 237, de 19/12/97 - Dispõe sobre licenciamento ambiental; competência da União, Estados e Municípios; listagem de atividades sujeitas ao licenciamento; Estudos Ambientais, Estudo de Impacto Ambiental e Relatório de Impacto Ambiental.

Resolução CONAMA n 335 , de 03/04/03 - Dispõe sobre o licenciamento ambiental de cemitérios.

Resolução CONAMA n 368, de 28/03/06 - Altera dispositivos da Resolução n 335, de 3 de abril de2003, que dispõe sobre o licenciamento ambiental de cemitérios.

Resolução CONAMA no 402, de 17/11/08 - Altera os artigos 11 e 12 da Resolução no 335, de 3 de abril de 2003.

LEI $11.445 / 2007$ - de 05/01/2007 - estabelece diretrizes nacionais para o saneamento básico; altera as leis $n^{\circ}$ 6.766, de 19 de dezembro de 1979, 8.036, de 11 de maio de 1990, 8.666, de 21 de junho de 1993, 8.987, de 13 de fevereiro de 1995; revoga a lei $n^{\circ} 6.528$.

LEI 10.257/2001 (Estatuto das Cidades) - 10/07/2001 - regulamenta os arts. 182 e 183 da constituição federal, estabelece diretrizes gerais da política urbana e dá outras providências. 
LEI 9.074/1995 - 07/07/1995 - estabelece normas para outorga e prorrogações das concessões e permissões de serviços públicos e dá outras providências.

Lei Complementar nㅇ 94, de 29/05/74 - Define normas acerca dos aspectos comuns que cercam os interesses dos municípios que compõem a RMSP (Região Metropolitana de São Paulo). Dentre eles, merecem destaque, para os fins deste relatório, os itens $\mathrm{III}$ e $\mathrm{VI}$ do artigo $2^{\circ}$, aproveitamento dos recursos hídricos e controle da poluição ambiental, na forma que dispuser a lei federal, respectivamente.

Lei no 997, de 31/05/76 - Dispõe sobre controle de poluição do meio ambiente.

KEMERICH, P. D. C.; SILVA, J. L. S.; BARROS, G.; BORBA, W. F.; UCKER, F. E.; FOLETTO, C. V. Caracterização química da água subterrânea em área ocupada por cemitério: uso da técnica de espectrometria de fluorescência de raios-X por energia dispersiva (EDXRF). Ambi-Agua, Taubaté, v. 7, n. 3, p. 166-182, 2012.

KEMERICH, P.D.C.; SILVA, P. R. B.; de Borba, W. F.; GERHARDT, A. E.; FLORES, C. E. B. Alteração Química em Solo Ocupado por Necrópole em Seberi - RS. In: 26ํㅜ Congresso Brasileiro de Engenharia Sanitária e Ambiental. Porto Alegre - RS, Anais, VI- 159, setembro de 2011.

KEMERICH, P. D. C.; Descovi Filho, L. L. V.; UCKER, F. E.; FOLETTO, C. V. Influência Dos Cemitérios Na Contaminação Da Água Subterrânea Em Santa Maria - RS. Águas Subterrâneas, v.24, n.1, p.129-141, 2010.

KEMERICH, P. D. C. - Influência Dos Cemitérios na Contaminação da Água Subterrânea em Santa Maria - RS - Águas Subterrâneas, v.24, n.1, p.129-141, 2010.

Resolução SMA 01/10 - Define procedimentos para o licenciamento ambiental de obras na área de influência do rio Tietê.

Resolução SMA 14/10 - Define as diretrizes técnicas para o licenciamento de empreendimentos em áreas potencialmente críticas para a utilização de água subterrânea.

Resolução SMA 18/07 - Disciplina procedimentos para a autorização de supressão de exemplares arbóreos nativos isolados

Resolução SMA 22/07 - Dispõe sobre a execução do Projeto Ambiental Estratégico "Licenciamento Ambiental Unificado", que visa integrar e unificar o licenciamento ambiental no Estado de São Paulo, altera procedimentos para o licenciamento das atividades que especifica e dá outras providências.

Resolução SMA 22/09 - Dispõe sobre a apresentação de certidões municipais de uso e ocupação do solo, sobre o exame e manifestação técnica pelas Prefeituras 
Municipais nos processos de licenciamento ambiental realizado no âmbito do SEAQUA e sobre a concessão de Licença de Operação para empreendimentos existentes e dá outras providências.

Resolução SMA oㅡ 42, de 29/12/94 - Define que, nos casos previstos no artigo $2^{\circ}$ da Resolução CONAMA no 1/86, o interessado requererá a licença ambiental instruída com Relatório Ambiental Preliminar - RAP, conforme roteiro de orientação estabelecido pela Secretaria de Estado do Meio Ambiente - SMA. 